\section{A Comparative Analysis of Teacher Education by Country}

\author{
Geoffrey A. Lawrance \\ University of Newcastle, NSW, Australia \\ David H. Palmer \\ University of Newcastle, NSW, Australia \\ Tel: 612-4921-5715Ｅ-mail: David.Palmer@newcastle.edu.au
}

Received: September 14, 2017 Accepted: October 19, 2017 Published: November 5, 2017 doi:10.5296/gjes.v3i2.11865

URL: https://doi.org/10.5296/gjes.v3i2.11865

\begin{abstract}
This essay is designed to provide a snapshot of teacher education practices in Australia compared to other western countries such as the UK, USA, Germany and France. The data for this work was obtained by document analysis. This type of study is important in order to provide the comparative perspective that is so important when evaluating the development of innovative approaches to teacher education.
\end{abstract}

Keywords: Teacher education, Comparative 


\section{Introduction}

The quality of teacher education is an important issue worldwide. Korthagen (2004) highlighted the process of reflection that is essential to the development of an effective framework for teacher education. Furthermore, he argued that questions such as "What are the essential qualities of a good teacher?" and "How can we help young people to become good teachers?" are questions that are not easy to answer in a definitive way. In these times when societies are increasingly becoming more complex, high quality teacher education is seen as an essential building block towards a well-educated population. The purpose of this paper is to provide an opportunity for teacher educators to reflect on some different approaches to teacher education.

Of particular note is that significant reforms of teacher education have occurred in many countries in the 1990s, following a period of reasonable stability, often lasting for decades. That initial teacher education has been swept up in the wider reforms of education was inevitable, but this has not limited the uncertainty and controversy associated with change. Of changes in countries such as France and England, it is the increased role of schools in teacher education and a deeper emphasis on the practice of teaching that is notable (Asher \& Malet 1999). The paper will begin by reviewing teacher education approaches in Australia, and will then provide a snapshot of teacher education in the UK, USA, Germany and France at the turn of the twenty-first century.

\section{Teacher Education in Australia}

In an increasingly corporate tertiary education world, training in education is big business. Today, approximately one in nine of university students are enrolled in a degree in education, with the effective full-time student unit load (EFTSU) accounting for approximately one twelfth of all national enrolments.

One consequence of the number of education students is that almost all universities are currently participating in the training of teachers in some fashion. Given the number of students involved, it is not surprising from a purely corporate viewpoint that the large majority of universities in Australia offer degrees in education; it is a group of students that is too large to dismiss when building a university profile and footprint. At the same time, of course, there are state and regional issues involved in offering training.

The size of education schools or departments varies greatly between universities. In initial teacher training, total number of students at individual universities range from approximately 90 to 2700 (DETYA, 2001), with a mean size of 965 (standard deviation 707). There are many substantial schools. However, the operation over a number of campuses and the range of degrees offered mean that relatively small cohorts of students may be involved in a particular program at any one site in some cases. For science, mathematics and technology specialists particularly, where enrolments represent around $15 \%$ of total enrolments, the number of candidates at any particular campus may be small.

The character and geographical reach of universities varies considerably, from multi-state through multi-campus to single campus in character. The focus of universities from broad 
teaching and research through broad teaching and selected research to restricted teaching and research institutes is also variable. This is related, in part, to their origins; for example, as preor post-unified system in establishment. In education, teaching may be restricted to a single campus of multi-campus universities or else may be broadly based. Whereas most operate separate education, science and technology faculties, this is by no means exclusive, with a small minority presenting a less divided system; for some, education and science faculties do not even operate on the same campus. Thus there is a diversity in character which acts as a background to the way universities approach their teacher education programs.

Usually, teacher training programs require from four to five years of full-time equivalent study. This may occur in a single four-year bachelors degree; in a four-year double degree program; in a one-year postgraduate diploma following prior completion of a three year non-education degree; or, in a postgraduate education component of from one to two years following a first non-education and leading to a second degree or masters in teaching.

The fields of specialization offered in each type of degree differ with degree type and with institution. It is apparent that institutions with overlapping regional footprints may feature different program specializations compared with their academic neighbors, as part of both competitive reality and a desire to create a distinctive character for their institutions. However, overall specializations offered are designed to match the requirements of employers, in particularly the relevant state education department. Some programs have a broad common character across the nation. For example, the vast majority of teachers training as pre-school teachers will be doing so in a single four-year degree program. This is also the case, but less so, in primary teacher training, whereas secondary teacher training exhibits the broadest variety of training modes. Of course, this is a broad generalization, which does not recognize the diversity of educational philosophies that drive what appear at first sight to be similar courses. What is apparent is that a combination of state-based education priorities, market forces, overarching university corporate policy and the dominant local educational philosophy contribute to a diversity of teaching approaches that are not immediately apparent. This is reflected in this project.

Teacher education in Australia has traditionally been a tertiary college or university based activity. These institutes have enjoyed a monopoly in teacher training essentially throughout the $20^{\text {th }}$ century. Whether this continues to be the case in the $21^{\text {st }}$ century is an issue that remains to be resolved (Jones, 2001). There are some who see value in school-based or even private provider-based training. Concerns that current initial teacher training may lag behind international developments, with teacher educators slow to adopt new teaching and learning strategies, are extant in the community. The validity of this view can be challenged. Faculties of Education in Australia are clearly productive in terms of their research output, ranking fifth in the world. Moreover, the recent DETYA report on The Impact of Educational Research (2000) concluded that a good deal of the research had practical application for teaching and policy development. The inference is that university-based educational research in Australia is of international standard, is aligned with debate and developments across the world, and contributes to the evolution of teacher training programs in Australia. 
What is evident from the above is the high level of participation by universities in initial teacher education, and the range of degree and diploma programs which have been developed to prepare teachers for our nation's schools. That a number of new degree programs are listed compared with 2001 is indicative of continuing change in the teacher education system. We presume these changes reflect contemporary philosophy and on-going research in teacher education.

Another concern for current teacher education programs is their capacity to attract academically gifted students. It is relevant to examine the University Admission Index (UAI) scores for various degree programs, although they represent only the lower limits and do not inform on spread of entering student scores. The average UAI entry requirements for all education programs are reasonably consistent and on only one occasion was a minimum over 80 applied. Secondly, these entry scores compare favorably with generalist degrees in arts and science.

However, specialist degrees, with the exception of nursing, had UAI cut-off scores above or even well above teaching, and ranging up to UAIs of greater than 90. Since these UAI scores reflect in part student demand, the inference is that teaching is not a high demand specialization. The academic abilities of students entering teacher education programs as measured by higher school certificate examination results, while not necessarily indicative of performance in university courses or practical teaching ability, are likely nevertheless to have some impact on the character of the programs and curricula that are offered.

With current initial teacher training supplied by universities or tertiary colleges, and with reasonably common legislative and department of education expectations across states, there is a reasonable expectation of sameness in curricula across the nation. This is only partly true. First, current initial teacher training employs a number of pathways to the achievement of teacher accreditation. Second, there are different educational philosophies extant, which are reflected in variations within teaching programs. Third, physical aspects such as the size of a particular student cohort, student-staff ratios, staff profile, available infrastructure and the type of partner schools involved in teaching practice play a role in influencing programs. These, in combination, lead to a level of diversity within a general framework, which may not be obvious at a superficial level.

Initial teacher training is involved with the preparation of teachers for a number of defined areas. Students may choose to train as pre-school, primary school, middle school or secondary school teachers, as well as in areas like special, adult and vocational education. This choice defines in what area they will receive registration to practice. Each field of study operates separate curricula, although there are invariably some common subjects in all universities where students from different areas may come together. The range of discipline areas taught within any degree program varies depending on universities, but all are seeking to satisfy the requirements of the major employers in the particular state in which they operate.

Some background to the range of teacher education programs across universities is provided below, gleaned from website and other published information. 


\subsection{Double Degree Programs}

Double (or combined) degree programs are the predominant mode of preparation of secondary school teachers entering university without any prior degree, particularly those having completed a higher school certificate or its equivalent. The use of the double degree for educating primary school teachers is also increasing. Both science education and mathematics education are common areas of specialization, whereas technology education is less commonly offered. In the design and technology area, this is in part related to the lack of facilities for teaching the program, although the reasons are complex. That the great majority of universities offer degree studies in science and mathematics also contributes to parallel education courses including the specializations.

The typical double degree, for example Bachelor of Science/Bachelor of Teaching, takes four years of full-time study and assigns approximately half of formal credit to education subjects and half to science or other discipline subjects. Discipline subjects are generally taught by the relevant discipline, with education students usually joining classes along with students taking other degrees. Required subjects typically include professional knowledge such as basic psychology, information technology and communication skills. Most students complete an approved level of training in two science disciplines and in some cases three. The theoretical basis of child development, learning theories, educational philosophy, curriculum theory, evaluation of learning, pedagogy and educational practice form a significant part (around 25 to $30 \%$ ) of training, whereas practicum occupies much less than half of that in credit terms.

\subsection{Single Degree Programs}

Single degree programs are offered across a range of specializations and are at present the predominant mode of preparation of preschool and primary teachers, as well as vocational and adult education teachers. However, some secondary school teachers are prepared by this type of program. These programs involve four years of educational training in all but two cases where a three-year program operates as well as four-year programs.

Typically, the science, mathematics and technology content for each primary education program is presented in courses specifically designed for these students. These reflect the different requirements for teaching at this level compared with secondary school. Generally, these courses are compulsory in the teacher education curriculum. Other required subjects typically include areas such as basic psychology, information technology and communication skills. Education-focused courses in child development, learning theories, educational philosophy, curriculum theory, evaluation of learning, pedagogy and educational practice form a significant part of training. Practicum in primary school classrooms occupies a small component of the overall course. Teaching practice in this degree occupies effectively the same credit and the same period of time is allocated as in the double degree programs.

The science, mathematics and technology component of primary teacher single degree education programs is smaller than that found in double degree programs, unless the key learning area elected by the student is in one of these fields. The minimum amount of science, mathematics and technology topics a student teacher must take is only around $10 \%$ of most 
programs.

\subsection{Second Degree or Postgraduate Coursework Masters Degree Programs}

For graduates who have already completed an applicable first degree and are seeking training as a teacher, the alternative to the diploma of education is to complete a second undergraduate degree in education or else a postgraduate coursework masters degree in education. These de-emphasize content knowledge and focus on education studies, curriculum method and practicum. This is because of assumptions about relevant discipline knowledge having been achieved in the prior degree. However, where insufficient appropriate subjects (i.e. relevant to disciplines taught in the school environment) have been studied in the prior degree, students may be required to take additional science, mathematics or technology subjects to satisfy the relevant state education department.

These programs run for from one to two years full-time or equivalent. Two-year full-time programs are dominant, and lead to a coursework masters degree or a bachelor of education or teaching degree qualification. For eight universities, one-and-a-half or even one-year bachelor of education or teaching programs exist. Typically the amount of practicum usually equates with that operated in the four-year single or double degree programs, but represents a higher percentage of the second degree programs simply because they run for a lesser total period of time. Some programs offer exit after one and a half years with a bachelors degree, or participation in an additional internship in a school to complete the masters. The latter option provides for, obviously, a much higher amount of practical in-class teaching experience. Semester- or term-long internships are popular in two-year programs.

\subsection{The Demand for Science Mathematics and Technology Teachers}

That there is a shortage of teachers nationally in science, mathematics and technology has been widely reported recently. There are two consequences for schools: experienced, highly qualified teachers in these disciplines are in demand and may tend to move to selective state and private schools; and, classes may be taught by teachers without strong formal training in the discipline subject they are required to teach. One response to the teacher shortfall has been the introduction of programs of teacher training which draw on mature people with appropriate workplace experiences or else apply retraining of qualified teachers from other fields, where significant over-supply exists, in the sciences and mathematics.

These are reasonable concerns, but do not (and, of course, were not intended to) offer a solution. The problem for the government is, of course, complex; put simply, is any teacher better than no teacher? An even deeper problem with teacher training is that, even when a student chooses to study education, participants in the program also have fixed perceptions about what type of teacher they wish to become. It is clear that science and technology are not popular even amongst teacher trainees. Presumably, this reflects, dominantly, views about science amidst teacher trainees more than it does career prospects, given that they would eventually work in the same system with a common remuneration structure. In fact, despite obvious over-supply in some key learning areas, students still choose such areas.

If traditional or standard entry routes are not supplying sufficient number of science, 
mathematics and technology teachers, alternative entry schemes may deliver suitably trained teachers. However, the demand amidst the public for retraining as teachers is still not large, and is unlikely to grow much without special scholarship support for students who likely have existing financial and family commitments, which impinge significantly on their ability to study.

In the recent Australian Council of Deans of Science commissioned national study of employment outcomes for science graduates between 1990-2000, What Did You Do With Your Science Degree? (McInnes, Hartley, \& Anderson 2001), it was noted that a basic pass degree provided an effective entry into employment for the large majority of graduates. Of respondents in their first job, $89 \%$ said it was either a desired career position or a stepping stone to the same. Moreover, the employment of science graduates overall did not feature science education highly. In fact, graduates who listed science education as their field of employment were effectively zero for computer science, only approximately $2 \%$ for mathematics graduates, and from 4-7\% for life and physical science graduates. Further study of those in the workforce was most likely to be taken in business or information technology. Education as a career for science graduates did not feature highly in the last decade.

Retraining programs, which focus on non-science graduates and persons without a degree but with some relevant experience, offer an alternative approach to meeting demand for teachers in the sciences and technology. The University of Newcastle is the biggest retrainer for the teaching service in New South Wales, through their 'Newcastle Program', directed towards curriculum areas with acute teacher shortages. This uses the principle of industry recognition of prior learning to give applicants advanced standing for the content side of their teacher qualification when placing them into a mainstream teacher education program. It requires:

- a minimum attainment of the level of Certificate 3 trade qualification;

- extensive expertise in industry which is relevant to their prospective teaching area

- a capacity and continued ability for life-long learning.

\section{Teacher Education Methods in Other Countries}

\subsection{The United Kingdom}

In England and Wales, the overwhelming majority of secondary school teachers are graduates who are trained via the Postgraduate Certificate of Education (PGCE), a one-year full-time course. This course is dominated by time spent in schools; 24 of the 36 weeks of the course are spent in schools, and only the remainder in a higher education institute. The government agency, the Teacher Training Agency (TTA) funds initial teacher training and is responsible for recruitment to the teaching profession. Provided trainee teachers meet the standards set by the TTA, they can attain Qualified Teacher Status (QTS). This is a challenging exercise, which requires them to attain appropriate standards in teaching and classroom management, assessment, planning, recording, reporting, accounting, and professional responsibilities. The pressures created by the government's skills tests have been implicated with the loss of good student teachers from the system in a recent press report (Thornton, 2001). Training institutes 
are subject to regular outcomes-based external evaluation by the Office for Standards in Education. These training providers are under great pressure in terms of meeting enrolment targets and compliance, since failure in these areas severely influences funding.

Despite, or perhaps because of, the rigorous professional program, recruitment has proved difficult in science, mathematics and design and technology in England and Wales. Some critics have suggested that there is a crisis in teacher recruitment. Further, there is evidence that trainee students may withdraw from teacher training because of financial problems or the perceived poor image of the profession (Chambers \& Roper, 2000). Certainly, the number of entrants to initial teacher training was $24 \%$ below target in 1998-99, with shortfalls in design and technology (46\%), mathematics (47\%) and information technology (44\%) particularly severe. Several schemes, lately the Secondary Shortage Subject Scheme, have been used to address these problems over the years. It has been suggested that financial incentives alone are insufficient (Whitehead \& Postlethwaite, 2000).

Teacher training in England and Wales has become homogeneous in the wake of a National Curriculum. The role of teachers in the partner schools working with higher education institutes in postgraduate initial teacher training has increased in importance. In fact, schools in England are permitted to form consortia to fully provide initial teacher training, challenging the traditional role of tertiary colleges. Both the School Centered Initial Teacher Training and Graduate Teacher Scheme do not require higher education institute involvement in the training program. The existence of a continuing valid role for higher education institutes in training has been probed (Williams \& Soares, 2000). They concluded that the expertise of higher education institutes in research and their associated broad overview of latest thinking in education represent the most important contribution they bring to the training partnership. Earlier studies have pointed to a stronger and critically important role for higher education, particularly with regard to elevating the status of teachers (Edwards, 1992).

Concern about the consistency and standard of school-based mentor training, including the rate of mentor turnover and high costs, exists. There is a view that, since the main purpose of schools is not initial teacher training, their priorities may not be conducive to teacher training. Learning how to teach is not simply copying a role model, and some preparatory work is necessary, which best resides with a tertiary institute. Support for a partnership between schools and tertiary institutes in initial teacher training attracts strong support from most interested parties, since there is recognition of their capacity to make effective complementary contributions. That papers by those in higher education institutes point to a crucial role for their institutes in teacher training could be cynically dismissed as self-serving. However, this not only reflects unfairly on the integrity of the researchers, but ignores parallel opinion beyond the tertiary environment.

\subsection{USA}

Education in the USA is state or district based. However, both school and teacher education programs are influenced by some overarching national policies and organizations. One such body is the National Board for Professional Teaching Standards. 
Most teacher education is via four-year degrees offered at state universities or four-year colleges. Teacher education institutions usually obtain program accreditation from the state in which they reside. Local two-year community and technical colleges may offer shorter certificate or associate degree programs in education, although the field of education represents only $\sim 1 \%$ of the total curriculum delivered through these colleges across the nation. Credit transfer from these shorter programs towards a four-year degree in a university or four-year college can usually be arranged.

Teacher education graduates usually require certification as a teacher from their state authority. Their registration requires that they have completed an approved teacher education program at an accredited four-year institution. Classroom practice teaching forms a part of the curriculum in all university programs, but is typically for a total of from only eight to twelve weeks.

As an example, the Western Washington University offers two programs leading to teacher certification in the state of Washington, the higher of which is a Masters in Teaching. Endorsable major areas of study are approved by the state, with certain minimum requirements of credit, knowledge and skills set. The program of study includes a full semester internship in a school. In Georgia, certification of graduates who complete approved programs at universities is governed by the Georgia Professional Standards Commission (Hart, 1997). Despite these quality control measures, a significant number of teachers are working without full credentials; this is estimated to be as high as $\sim 14 \%$ in California, mostly in urban areas.

There are concerns in the USA about a growing shortage of qualified elementary and secondary school teachers, as expressed by Secretary of Education, Richard Riley (1999). Further, the preparedness of new teachers for teaching, with over $60 \%$ of graduates in one survey feeling they were not well prepared to implement state or district curricula. Partly, this relates to high percentages not having academic majors appropriate to their teaching tasks. These issues appear in a report from the National Center for Education Statistics, Teacher Quality: A Report on the Preparation and Qualifications of Public School Teachers, summarized by Barlow (1999). One proposed solution has been a call for an expanded role for community colleges in teacher training and recruitment (Gerdeman, 2001), through better articulation agreements and partnerships with four-year institutions. State authorities now encourage articulation arrangements. One example of current developments is the University of Illinois at Chicago - Community College Collaborative for Excellence in Teacher Preparation. This interaction of UIC with six local community colleges is funded under a National Science Foundation grant, with its purpose being to increase mathematics and science teacher candidates.

Changes to the education of teachers in the universities are also starting to appear (Darling-Hammond, 1999). Over three hundred have created new programs that extend beyond the traditional four-year degree. These new programs also include stronger partnerships with local schools. Some of these new programs are graduate entry programs for those with a prior discipline degree, and offer one or two years of teacher education. Others are five-year undergraduate entry programs that allow for a year-long school-based internship at the end of the program. Professional development programs devoted to formalizing and monitoring the 
classroom work of novice teachers, established with the assistance of local school districts, have also gained a foothold.

\subsection{Germany}

Each state in the German Federation has a large measure of autonomy in terms of arranging its school system and teacher education programs. There are over-arching directives from the federal department of education (Kultusministerium), and an assembly of state ministers of education and cultural affairs (Standige Konferenz der Kultusminister der Lander) serves to assure a reasonable degree of commonality while permitting a level of diversity.

Schools, both public and private, are under state supervision. At secondary level, there are three distinctive levels of schooling: Hauptschule (with a practical vocational orientation), Realschule (technical vocational orientation), and the Gymnasium (academic orientation). The latter provides the major route for university entrance. This tripartite system naturally involves a high level of stranding of students, and some states provide additional comprehensive schools as an option. However, the belief in differentiation and specialization in secondary education is dominant, and this is reflected in a parallel segregation of teacher training.

In the tripartite system, each type of school is staffed with teachers trained especially for that school (Jones, 2000). Teachers undertake university education followed by a period of practical training (up to two years) and assessment in a teacher training college (Lehrerseminar), or else take their full training program at the college over a longer period. The period of education is longer for Realschule and Gymnasium teachers (4-6 years) compared to Hauptschule teachers (3-4 years). The distinctive training and qualifications for the different programs is reflected in different salaries, teaching hours and status. Trainee teachers receive a salary, and when they become teachers are usually appointed as civil servants.

The teacher training institutes in Germany operate practically and administratively separate from the general university system, under the control of the state department of education. The Kultusministerium is responsible for establishing the centralised curriculum framework, while the Lehrerseminar are responsible for program delivery and assessment. Training occurs in partnership with schools (Seminarschulen), in which full-time teachers act as mentors.

All three streams of teacher education involve an induction and orientation stage initially, followed by broader professional development. Trainee teachers are selected for training on the basis of their subject knowledge, and teacher training concentrates on teaching methodology and practice. Approximately half their time is spent in classrooms in the early stages, extending to up to four days a week. Trainee teachers usually spend their time in just one host school. The partnership between school and college is well developed.

Despite a growing public unease with the school system and growing criticism of teachers, graduates are still opting to become teachers. Germany is one of very few countries where there is at present a surplus of science teachers.

\subsection{France}

There has been a profound change in teacher education in France, as in England. However, the 
direction of the change has differed substantially. Major reform commenced in France in 1991. It was directed first towards degree-level training for both primary and secondary teachers, closing an existing gap. Secondly, it sought to strengthen links between theory and practice in initial teacher training (Bonnet, 1996). To lead these changes, old-style training institutes were replaced with new institutes known as Institut Universitaire de Formation des Maitres (IUFM), public institutes under the control of the Minister for Higher Education, with a clearer and stronger focus on classroom practice.

Teacher education in France is at postgraduate level. Entry requires a degree or three years of equivalent study subsequent to the baccalaureat, and is achieved through application to the IUFM for a place. For secondary teachers, it is a two-year program of full-time study. The first year is dominantly academic study, with a single week of classroom observation. If successful, students more to the second year, which comprises classroom placement for six hours per week, with associated coursework in pedagogy and teaching methodology. Classroom practice involves a school-based mentor and some observation by an institute-based tutor. There is a greater emphasis on academic training over professional training in France compared with England (Foster, 2000). Qualified teacher status (titularisation) involves assessment by a committee including national inspectors, school teachers and university academics. All qualified teachers are civil servants and state employees.

France is facing a severe teaching shortage, which has produced efforts to attract new graduates to the profession (Marshall, 2000). Teacher education in France faces further reform (Marshall, 2001), relating to an effort to enhance subject knowledge and provide for more classroom experience before teachers enter their profession. Most students in the present system have been pointing to insufficient development of classroom skills. Further, the need for ongoing professional skills training of teachers new to teaching is being recognized. These changes were introduced in the last quarter of 2001.

\section{Conclusion}

Teacher training in most countries falls into two broad categories, being either centralized in a national system or decentralized into state or regional systems. The state-based system in Australia has close parallels in countries such as the USA and Germany. Centralized systems are found, not surprisingly, in most small countries such as New Zealand (Bell et al., 1995), but also in larger countries such as the UK and France. Further, the mechanisms of teacher training varies from country to country, from being based in special tertiary education colleges, in broad-spectrum universities, to being potentially entirely school-based. There is no clear ownership of wisdom in initial teacher training, although in almost all developed countries teaching is now a graduate profession. Further, there has been an increasing emphasis on assessment of teacher competency and quality assessment.

\section{References}

Asher, C., \& Malet, R. (1999). Initial teacher training in the post-reform period: A sample of student opinion in England and France. Compare, 29(1), 71-83. https://doi.org/10.1080/0305792990290106 
Barlow, D. (1999). Are our teachers well prepared? The Education Digest, 64(8), 44-47.

Bell, B., Jones, A., \& Carr, M. (1995). The development of the recent National New Zealand Science Curriculum. Studies in Science Education, 26, 73-105. https://doi.org/10.1080/03057269508560072

Bonnet, G. (1996). The reform of initial teacher training in France. Journal of Education for Teaching, 22, 249-269. https://doi.org/10.1080/02607479620232

Chambers, G. N., \& Roper, T. (2000). Why students withdraw from initial teacher training. Journal of Education for Teaching, 26(1), 25-43. https://doi.org/10.1080/02607470050007110

Darling-Hammond, L. (1999). America's future: Educating teachers. The Education Digest, 64(9), 18-23.

DETYA. (2000). The Impact of Educational Research. Research Evaluation Program DETYA Report No. 6646. HERC00A, Australian Government Printing Office, Canberra.

DETYA. (2001). Statistical information on tertiary education Retrieved from http://www.detya.gov.au/tenfields/education/under.html

Edwards, T. (1992). Issues and challenges in initial teacher education. Cambridge Journal of Education, 22, 283-291. https://doi.org/10.1080/0305764920220302

Foster, R. (2000). Becoming a secondary teacher in France: A trainee perspective on recent developments in initial teacher training. Educational Studies, 26(1), 5-17. https://doi.org/10.1080/03055690097709

Gerdeman, R. D. (2001). The role of community colleges in training tomorrow's school teachers. Community College Review, 28(4), 62-76. https://doi.org/10.1177/009155210102800404

Hart, L. F. (1997). Mathematics and science teacher education and school reform: A statewide process in Georgia. Action in Teacher Education, 19(10), 16-27. https://doi.org/10.1080/01626620.1997.10462850

Jones, M. (2000). Becoming a secondary teacher in Germany: A trainee perspective on recent developments in initial teacher training in Germany. European Journal of Teacher Education, 23(1), 65-71. https://doi.org/10.1080/026197600411634

Jones, P. (2001). Educators face generation lag. The Australian, Higher Education Supplement, Wednesday 9 May.

Korthagen, F. A. J. (2004). In search of the essence of a good teacher: Towards a more holistic approach to teacher education. Teaching and Teacher Education, 20, 77-97. https://doi.org/10.1016/j.tate.2003.10.002

Marshall, J. (2000). French lose their taste for teaching. The Times, Higher Education Supplement, Feb 9, p. 11.

Marshall, J. (2001). Teacher training overhaul. The Times, Higher Education Supplement, Mar 


\section{Macrothink}

Global Journal of Educational Studies

ISSN 2377-3936

2017, Vol. 3, No. 2

2, p.11.

McInnes, C., Hartley, R., \& Anderson, M. (2001). What Did You Do With Your Science Degree? A national study of employment outcomes for Science degree holders 1990-2000. Australian Council of Deans of Science, University of Melbourne.

Riley, R. (1999). New challenges, a new resolve: Moving American education into the $21^{\text {st }}$ century. The $6^{\text {th }}$ Annual State of American Education Speech, Long Beach, CA (ERIC Document Reproduction Service No. ED428052).

Thornton, K. (2001). Test pressure forces able trainees to quit. The Times, Higher Education Supplement, May 4.

Whitehead, J., \& Postlethwaite, K. (2000). Recruitment, access and retention: Some issues for secondary initial teacher education in the current social context. Research in Education, 64, 44. https://doi.org/10.7227/RIE.64.5

Williams, A., \& Soares, A. (2000). The role of higher education in the initial training of secondary school teachers: The views of the key participants. Journal of Education for Teaching, 26(3), 225-244. https://doi.org/10.1080/713676890

\section{Copyright Disclaimer}

Copyright for this article is retained by the author(s), with first publication rights granted to the journal.

This is an open-access article distributed under the terms and conditions of the Creative Commons Attribution license (http://creativecommons.org/licenses/by/3.0/). 